\title{
Geographic variation in surgical practice patterns and outcomes for resected nonmetastatic gastric cancer in Ontario
}

\author{
A.L. Mahar PhD, ${ }^{* \dagger}$ A. El-Sedfy $\mathrm{MD}^{*}{ }^{*}$ M. Dixon $\mathrm{MD}^{* \neq}{ }^{* \neq}$ M. Siddiqui $\mathrm{BSc}^{*}{ }^{*}$ M. Elmi MD, ${ }^{*}$ A. Ritter MD, ${ }^{*}$

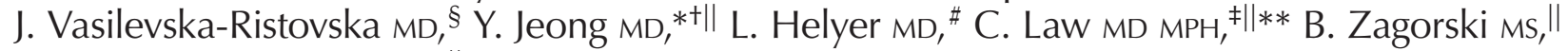 \\ and N.G. Coburn MD MPH${ }^{\neq \| * *}$
}

\begin{abstract}
Background Gastrectomy with negative resection margins and adequate lymph node dissection is the cornerstone of curative treatment for gastric cancer (GC). However, gastrectomy is a complex and invasive operation with significant morbidity and mortality. Little is known about surgical practice patterns or short- and long-term outcomes in earlystage GC in Canada.
\end{abstract}

Methods We undertook a population-based retrospective cohort study of patients with GC diagnosed between 1 April 2005 and 31 March 2008. Chart review provided clinical and operative details such as disease stage, primary tumour location, surgical approach, operation, lymph nodes, and resection margins. Administrative data provided patient demographics, geography, and vital status. Variations in treatment and outcomes were compared for 14 local health integration networks. Descriptive statistics and log-rank tests were used to examine geographic variation.

Results We identified 722 patients with nonmetastatic resected Gc. We documented significant provincial variation in case mix, including primary tumour location, stage at diagnosis, and tumour grade. Short-term surgical outcomes varied across the province. The percentage of patients with 15 or fewer lymph nodes removed and examined varied from $41.8 \%$ to $73.8 \%$ ( $p=0.02$ ), and the rate of positive surgical margins ranged from $15.2 \%$ to $50.0 \%(p=0.002)$. The 30 -day surgical mortality rates did not vary statistically significantly across the province $(p=0.13)$; however, rates ranged from $0 \%$ to $16.7 \%$. Overall 5 -year survival was $44 \%$ and ranged from $31 \%$ to $55 \%$ across the province.

Conclusions This cohort of patients with resected stages I-III GC is the largest analyzed in Canada, providing important historical information about treatment outcomes. Understanding the causes of regional variation will support interventions aiming to improve GC operative outcomes in the cancer system.

Key Words Surgery, prognosis, variations

Curr Oncol. 2018 Oct;25(5):e436-e443

www.current-oncology.com

\section{INTRODUCTION}

Gastric cancer (GC) is a rare and often fatal diagnosis ${ }^{1}$. Gastrectomy with negative resection margins and adequate lymph node dissection are fundamental to curative treatment for GC. Gastrectomy is a complex and invasive operation with significant morbidity and mortality. Patient outcomes are determined by the experience and knowledge of the health care team and by institutional volume and resources $^{2,3}$. Surveys of surgeons and pathologists in Canada, and a review of endoscopy reports, suggest a lack of understanding and awareness of best practices, which could lead to practice variation and suboptimal patient outcomes ${ }^{4-6}$.

Compliance with treatment guidelines is associated with better prognosis ${ }^{7-9}$. In Canada, it is unclear how many patients with potentially curable GC receive treatment adherent to surgical practice recommendations ${ }^{10}$. International and national guidelines recommend resection margins of $4 \mathrm{~cm}$ or more and the dissection of at least 16 nodes to accurately stage the patient and improve 
survival ${ }^{11-13}$. Given the low incidence of GC, there is a strong potential for regional variation in outcomes. Variation in the management and outcomes of metastatic Gc has been previously documented ${ }^{14}$. Achieving equity in outcomes across geographic regions to improve prognosis for GC patients is an achievable goal; however, very few Canadian data are available to guide improvement in clinical outcomes. The objective of the present work was therefore to describe and compare the demographics, clinical practices, and outcomes in resected GC across the regions of Ontario such that areas for surveillance and monitoring for quality improvement could be identified.

\section{METHODS}

\section{Study Design and Population}

This retrospective, population-based cohort study of patients with resected nonmetastatic GC diagnosed and treated in Ontario included patients 18 years of age and older with a diagnosis of GC recorded in the Ontario Cancer Registry between 1 April 2005 and 31 March 2008. Patients with multiple cancers, no corresponding hospital chart, a tumour located primarily in the esophagus, non-adenocarcinoma histology, metastatic disease, and no gastrectomy were excluded from the analysis.

\section{Data Sources and Collection}

For the study, data from a province-wide chart review were linked with health care administrative data housed at the Institute for Clinical Evaluative Sciences. Follow-up in the administrative databases was complete to 31 March 2012. The project received approval from the research ethics boards at Sunnybrook Health Sciences Centre and adhered to all privacy and confidentiality regulations of the Institute for Clinical Evaluative Sciences.

\section{Chart Review}

The province-wide chart review was conducted at 116 institutions across Ontario between November 2009 and November 2011. For all sites, the chart review data were collected by a specially trained physician abstractor (JVR). Data for $40 \%$ of the patients were collected from more than one hospital, and information from multiple endoscopy, radiology, and pathology reports was included for each patient. Additional abstraction of data from operative reports for each cancer-directed surgery was completed by a surgical resident (MD) in 2013. The chart review data were linked to vital status data in 2013. Between 2014 and 2016, a staging algorithm to assign TNM stage according to the American Joint Committee on Cancer staging system (7th edition) was developed based on combined data from the chart review. The algorithm used all primary sources of information available in the charts.

\section{Routinely Collected Health Care Data}

The chart review data were linked by encrypted identifier with the oHIP (Ontario Health Insurance Plan) database, the Discharge Abstract Database maintained by the Canadian Institute for Health Information, the Cancer Care Ontario Activity Level Reporting database, and the Registered Persons Database.
The OHIP database, which contains physician billing claims, was used to identify receipt of chemotherapy, dates of surgeries, and some information on surgery type. The Discharge Abstract Database provided administrative and clinical information for all hospitalizations, including data about surgical and nonsurgical interventions. The Activity Level Reporting database, which houses information about cancer treatment provided in regional cancer centres, was used to identify receipt of radiation. The Registered Persons Database provided sociodemographic and vital status data for the study population.

\section{Geographic Variation}

Using postal codes, patients were assigned to a geographic area of residence and were classified into a local health integration network (LHIN). The LHINS, which correspond to the 14 geographically defined areas responsible for health care services coordination and delivery across the province (http://www.lhins.on.ca/home.aspx), were each randomly labelled with a number.

\section{Surgical Outcomes}

A combination of chart review and routinely collected health care data from physician billing and hospitalization records were used to define the surgical approach (laparoscopic vs. open), type of surgery (proximal gastrectomy, distal gastrectomy, total gastrectomy), and time from diagnosis to surgery (days between the diagnosis date and the surgery date). Data from the pathology report for the surgical specimen and the operative notes were used to identify the number of lymph nodes examined (numeric), and the status of surgical resection margins (microscopically or macroscopically positive or negative). Vital status data from the routinely collected health care data were used to determine in-hospital mortality and long-term survival from the date of diagnosis. Death from any cause was considered an event. Patients still alive were censored at the study end date (31 March 2012) or at 60 months, whichever came first.

\section{Patient, Disease, and Clinical Characteristics}

Age at diagnosis, sex, score on the Charlson comorbidity index, income quintile, and rurality of residence were obtained. Comorbidity was measured using the Deyo modification to the Charlson comorbidity index. Median community income quintile was used as a proxy for socioeconomic status, and patients were categorized using aggregate census income data (lowest to highest). Rural status, as defined by Statistics Canada, indicates a community size of less than 10,000 inhabitants. Tumour location was determined from preoperative endoscopy reports and classified as gastroesophageal junction, proximal stomach, mid-stomach, distal stomach, entire stomach, or unknown. Tumour grade was obtained from the pathology report for the resection specimen and was categorized as well-differentiated, moderately well-differentiated, poorly differentiated, undifferentiated, and unknown.

\section{Statistical Analyses}

Descriptive statistics are presented and compared by LHIN to explore geographic variation. Kruskal-Wallis tests were 
used for skewed continuous data, and chi-square tests, for categorical data. We used box plots to describe inter-LHIN variation for key outcomes. The line across the middle of the box marks the median, with the top and bottom edges of the box denoting the upper and lower quartiles. Whiskers represent data falling outside the middle $50 \%$, and circles represent outliers. The Kaplan-Meier method was used to calculate the median 1- and 5-year survivals. Survival curves were compared using the Wilcoxon rank sum test. Data cells containing fewer than 6 patients are suppressed in accordance with privacy and confidentiality regulations established by the Institute for Clinical Evaluative Sciences and the Information and Privacy Commissioner for Ontario. All analyses were performed using the SAS software application (version 9.2: SAS Institute, Cary, NC, U.S.A.).

\section{RESULTS}

We identified 722 patients with nonmetastatic resected GC during the study time period (Figure 1); approximately $92 \%$ of the patients with stages I-III disease underwent surgical resection. Table I describes the demographic and clinical characteristics of the patients and their distribution across the province.

All LHINs carried out resections for patients with GC; 5 LHINs each performed 10 or fewer GC resections annually during the study period. Of patients receiving a surgical resection, $48.9 \%$ were 70 years of age or older at the time of diagnosis, and $65.5 \%$ were men. Of patients who underwent resection, $22 \%$ had a tumour in the gastroesophageal junction, and $48.5 \%$ had stage III GC at the time of diagnosis. On surgical pathology, $47 \%$ of tumours were classified as poorly differentiated; however, very few additional pathology data were available in the reports. We documented significant geographic variation in sex, rurality of residence, median community income, primary tumour location, tumour grade, depth of tumour invasion, and stage at diagnosis.

Table II describes the variation in surgical practice patterns and nonsurgical oncologic treatment modalities across the province. The median time to gastrectomy varied significantly, ranging from 27 days to 60 days ( $p=$ $0.001)$. The operation most commonly performed was distal gastrectomy; however, the type of operation performed showed significant geographic variation $(p<0.001)$. The percentage of patients receiving a total gastrectomy ranged from $20 \%$ to $56 \%$, depending on the LHIN. Gastrectomy was most commonly performed using an open approach, although the use of laparoscopic or laparoscopy-assisted methods varied significantly across the province (range: $0 \%-9.5 \% ; p<0.001)$. In a number of LHINS, surgeons performed no laparoscopic resections during the study period. Of these patients undergoing resection, $42 \%$ received blood transfusions; the percentage receiving at least 1 transfusion did not vary significantly across the LHINs. In addition to surgery, $48.3 \%$ and $39.5 \%$ of patients received chemotherapy and radiotherapy respectively. Use of radiotherapy varied significantly across the province $(p=0.007)$. Very few patients $(n=34)$ received preoperative chemotherapy. Figure 2 depicts the inter-LHIN variation in the use of chemotherapy and radiotherapy.
Surgical outcomes-including rates of positive surgical margins and of patients who did not receive an adequate lymphadenectomy—varied significantly across the province. The average proximal margin was $4.0 \mathrm{~cm}$ (range: $3.0-5.4 \mathrm{~cm}$ depending on the LHIN; $p<0.001$ ), and the average distal margin was $4.2 \mathrm{~cm}$ (range: $2.5-4.7 \mathrm{~cm}$ depending on the LHIN; $p=0.95$ ). The median number lymph nodes examined was 14 , and the overall number varied significantly by LHIN (range: 9-19 nodes; $p=0.02$ ). In-hospital mortality was not statistically significantly different across the province, although it ranged from $0 \%$ to $16.7 \%$ ( $p=0.13$ ). Figure 3 shows inter-LHIN variation in select surgical outcomes.

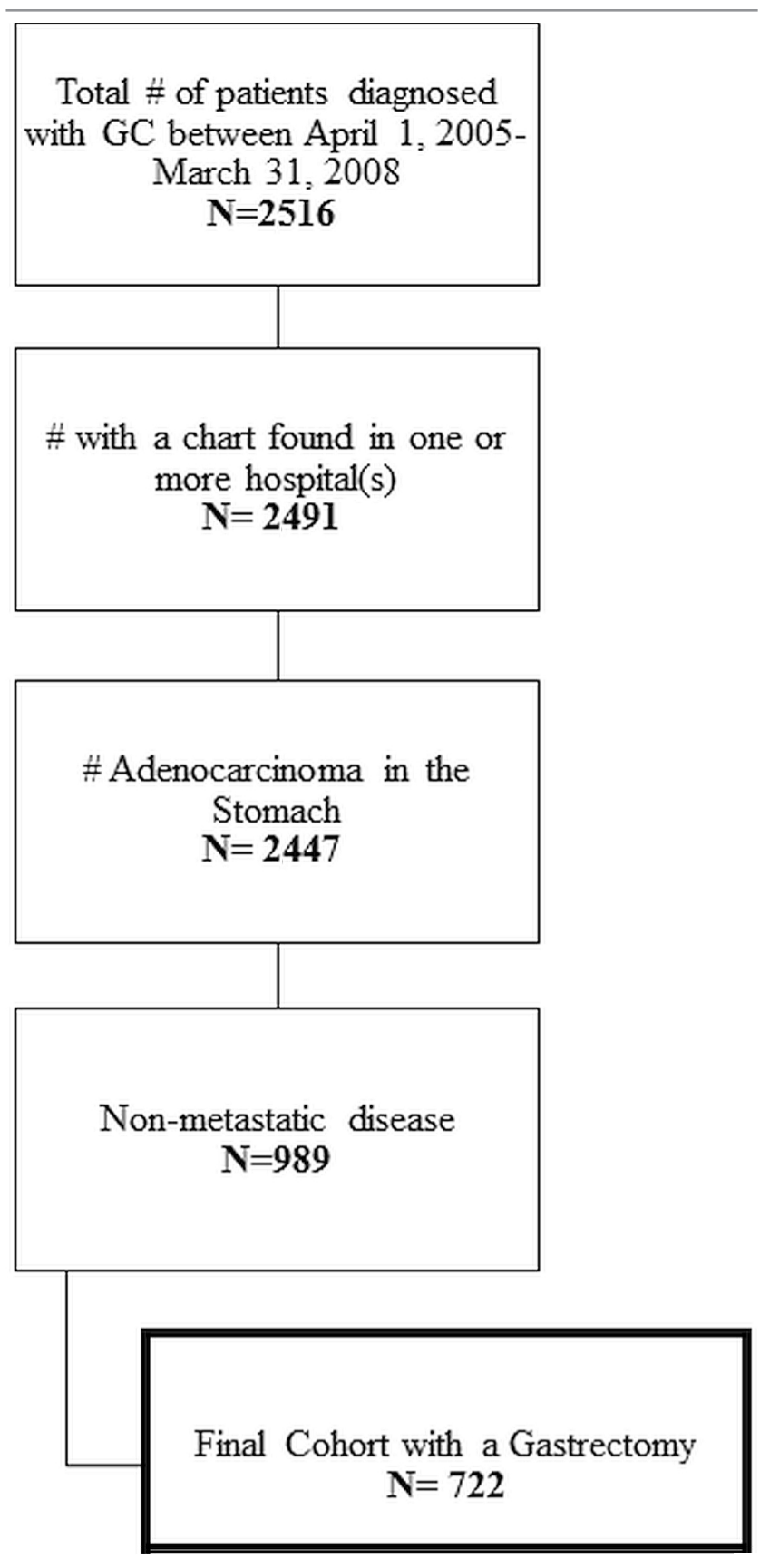

FIGURE 1 Creation of the study cohort. GC = gastric cancer. 
GEOGRAPHIC VARIATION IN SHORT-TERM OUTCOMES FOR RESECTED GASTRIC CANCER, Mahar et al.

TABLE I Range in demographic and clinical characteristics of 722 patients with nonmetastatic, surgically resected stomach cancer managed across Ontario

\begin{tabular}{|c|c|c|c|}
\hline \multirow[t]{2}{*}{ Characteristic } & \multicolumn{2}{|c|}{ Patient group (\%) } & \multirow{2}{*}{$\underset{\text { Value }^{b}}{p}$} \\
\hline & Ontario overall & LHIN range ${ }^{a}$ & \\
\hline Age group at diagnosis & & & 0.36 \\
\hline$<50$ Years & 8.3 & & \\
\hline 50-54 Years & 7.1 & & \\
\hline 55-59 Years & 10.1 & & \\
\hline 60-64 Years & 12.3 & & \\
\hline 65-69 Years & 13.0 & & \\
\hline$\geq 70$ Years & 48.9 & $33.3-70.4$ & \\
\hline Sex (men) & 65.5 & $33.3-75.8$ & 0.09 \\
\hline Score on the Charlson comorbidity index & & & 0.94 \\
\hline No prior hospitalization & 48.1 & & \\
\hline 0 & 33.1 & & \\
\hline$\geq 1$ & 18.8 & $15.8-25.9$ & \\
\hline Median community income quintile & & & $<0.001$ \\
\hline Lowest & 19.4 & $9.5-27.4$ & \\
\hline 2 & 19.4 & & \\
\hline 3 & 20.8 & & \\
\hline 4 & 21.6 & & \\
\hline Highest & 18.6 & & \\
\hline Rural residence & 10.5 & $0-55.6$ & $<0.001$ \\
\hline \multicolumn{4}{|l|}{ Local health integration network } \\
\hline 11 & 8.6 & \multirow{14}{*}{ NA } & \\
\hline 14 & 2.2 & & \\
\hline 16 & 4.2 & & \\
\hline 17 & 2.6 & & \\
\hline 18 & 1.2 & & \\
\hline 70 & 5.8 & & \\
\hline 71 & 3.7 & & \\
\hline 72 & 9.1 & & \\
\hline 73 & 10.9 & & \\
\hline 74 & 6.8 & & \\
\hline 75 & 10.1 & & \\
\hline 76 & 6.0 & & \\
\hline 78 & 11.6 & & \\
\hline 79 & 17.0 & & \\
\hline Tumour location & & \multirow{7}{*}{$0-51.0$} & \multirow[t]{7}{*}{$<0.001$} \\
\hline Distal & 47.4 & & \\
\hline Entire & 4.4 & & \\
\hline Gastroesophageal junction & 22.0 & & \\
\hline Middle & 18.3 & & \\
\hline Proximal & 5.4 & & \\
\hline Unknown & 2.5 & & \\
\hline Tumour grade ${ }^{c}$ & & \multirow{6}{*}{$18.8-57.9$} & \multirow[t]{6}{*}{$<0.001$} \\
\hline Well differentiated & 7.9 & & \\
\hline Moderately well differentiated & 32.5 & & \\
\hline Poorly differentiated & 46.7 & & \\
\hline Undifferentiated & 3.3 & & \\
\hline Not documented & 9.5 & & \\
\hline
\end{tabular}


TABLE I Continued

\begin{tabular}{|c|c|c|c|}
\hline \multirow[t]{2}{*}{ Characteristic } & \multicolumn{2}{|c|}{ Patient group $(\%)$} & \multirow{2}{*}{$\underset{\text { Value }^{b}}{p}$} \\
\hline & Ontario overall & LHIN range ${ }^{a}$ & \\
\hline Depth of tumour invasion ${ }^{d}$ & & & 0.02 \\
\hline No evidence of primary tumour, or carcinoma in situ & 2.6 & & \\
\hline Tumour invades lamina propria or submucosa & 15.2 & & \\
\hline Tumour invades muscularis propria or subserosa & 16.3 & & \\
\hline Tumour invades subserosa & 23.4 & & \\
\hline Tumour penetrates serosa (visceral peritoneum) & 27.0 & $16.7-44.4$ & \\
\hline Tumour invades adjacent structures & 12.9 & $0-26.5$ & \\
\hline AJCC stage ${ }^{e}$ & & & 0.07 \\
\hline I & 24.9 & $11-33.3$ & \\
\hline II & 23.4 & $6.7-35.7$ & \\
\hline III & 48.5 & $31.3-88.9$ & \\
\hline
\end{tabular}

a Because of small sample sizes and reporting guidelines from the Institute for Clinical Evaluative Sciences, ranges (minimum-maximum) are presented for "worst" categories only.

b Comparing full distributions across the local health integration networks.

c $1.1 \%$ unknown.

d $2.5 \%$ not documented.

e $3.2 \%$ unknown.

TABLE II Variation in practice patterns for 722 patients with surgically resected nonmetastatic stomach cancer in Ontario

\begin{tabular}{|c|c|c|c|}
\hline \multirow[t]{2}{*}{ Variable } & \multicolumn{2}{|c|}{ Patient group } & \multirow{2}{*}{$\begin{array}{c}p \\
\text { Value }\end{array}$} \\
\hline & $\begin{array}{c}\text { Ontario } \\
\text { overall }\end{array}$ & $\begin{array}{c}\text { LHIN } \\
\text { range }^{\mathrm{a}}\end{array}$ & \\
\hline Time to surgery (days) & & & 0.001 \\
\hline Median & 32 & $27-60$ & \\
\hline Interquartile range & $16-52$ & & \\
\hline Operation (\%) & & & $<0.001$ \\
\hline Proximal & 20.2 & $0-36.9$ & \\
\hline Distal & 52.9 & $26.5-64.6$ & \\
\hline Total & 26.5 & $20.3-55.6$ & \\
\hline Laparoscopic approach (\%) & 9.1 & $0-9.5$ & $<0.001$ \\
\hline Positive surgical margin or margins (\%) & 27.7 & $15.2-50.0$ & 0.002 \\
\hline \multicolumn{4}{|l|}{ Lymph nodes examined ${ }^{b}$} \\
\hline Median (n) & 14 & $9-19$ & 0.04 \\
\hline Interquartile range $(n)$ & $8-20$ & & \\
\hline$<16$ Nodes $(\%)$ & 60.4 & $41.8-73.8$ & 0.02 \\
\hline In-hospital mortality (\%) & 5.1 & $0-16.7$ & 0.13 \\
\hline \multicolumn{4}{|l|}{ Nonsurgical treatment modalities (\%) } \\
\hline Chemotherapy & 48.3 & $33.3-58.1$ & 0.27 \\
\hline Radiotherapy & 39.5 & $19.7-56.0$ & 0.007 \\
\hline Blood transfusions & 42 & $37.5-55.6$ & 0.27 \\
\hline
\end{tabular}

a Because of small sample sizes and reporting guidelines from the Institute for Clinical Evaluative Sciences, ranges (minimummaximum) are presented for "worst" categories only.

b Missing for $3.3 \%$ of the cohort.

In the entire cohort, 1-year survival was $79 \%$ and 5 -year survival was $44 \%$. Median survival duration was 32

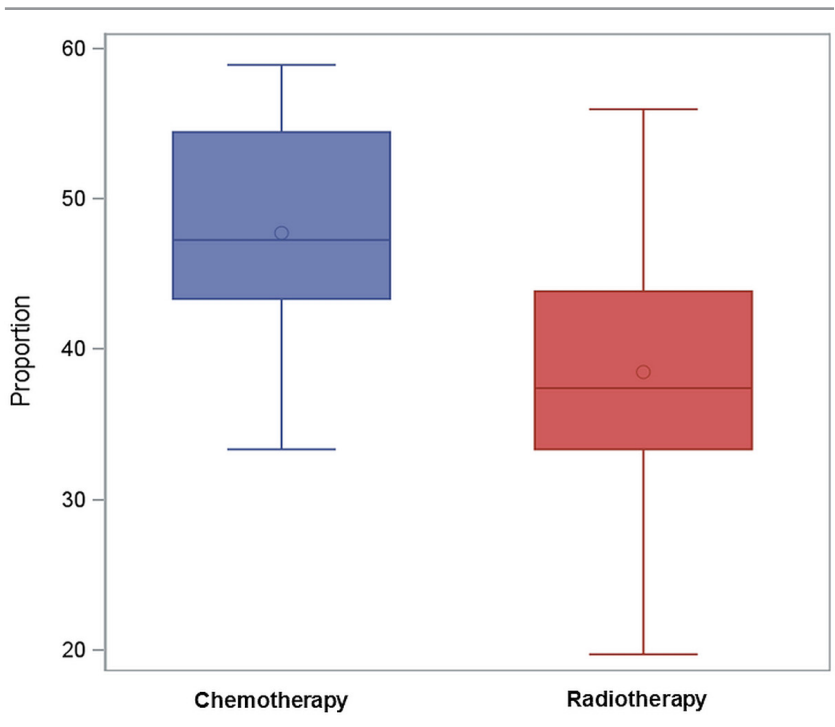

FIGURE 2 Variation in receipt of chemotherapy and radiotherapy for 722 patients with resected gastric cancer in 14 local health integration networks.

months ( $95 \%$ confidence interval: 25 months to 38 months). Figure 4 depicts survival by stage at diagnosis. For stages I, II, and III GC, the 5 -year overall survival (os) was $71 \%, 51 \%$, and $27 \%$ respectively $(p<0.001)$. The os varied significantly by resection margin status ( $p<0.001$, Figure 5 ) and was significantly better for patients with a negative resection margin, with 1-year survival being $84 \%$ and $67 \%$ and 5 -year survival being $51 \%$ and $27 \%$ for patients with negative compared with positive margins. Unadjusted os did not vary significantly across the LHINs ( $p=0.12)$, although variation in the rate was large (Figure 6); 1-year survival ranged from $58 \%$ to $94 \%$, and 5 -year survival ranged from $31 \%$ to $56 \%$. 


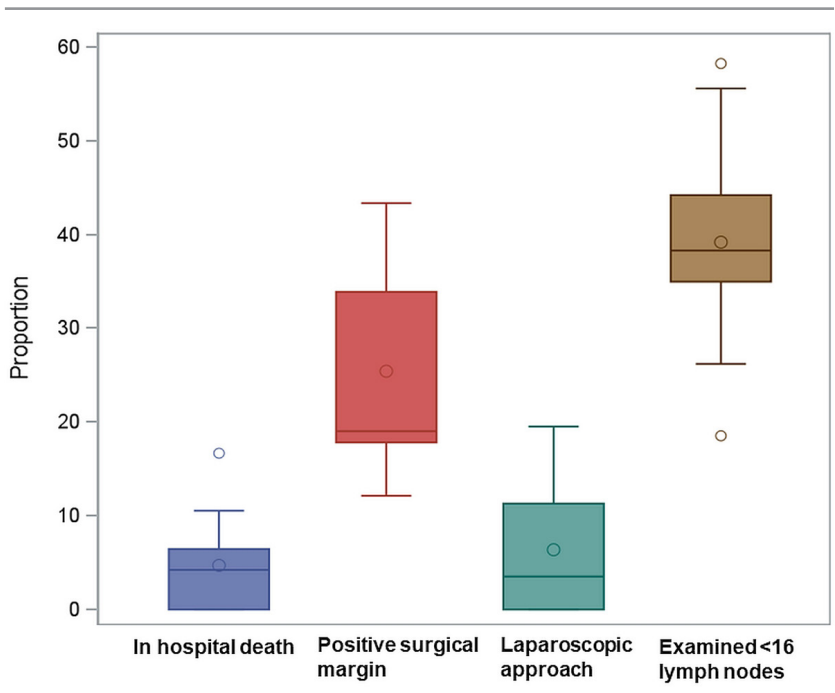

FIGURE 3 Variation in select surgical outcomes for 722 patients with resected gastric cancer in 14 local health integration networks.

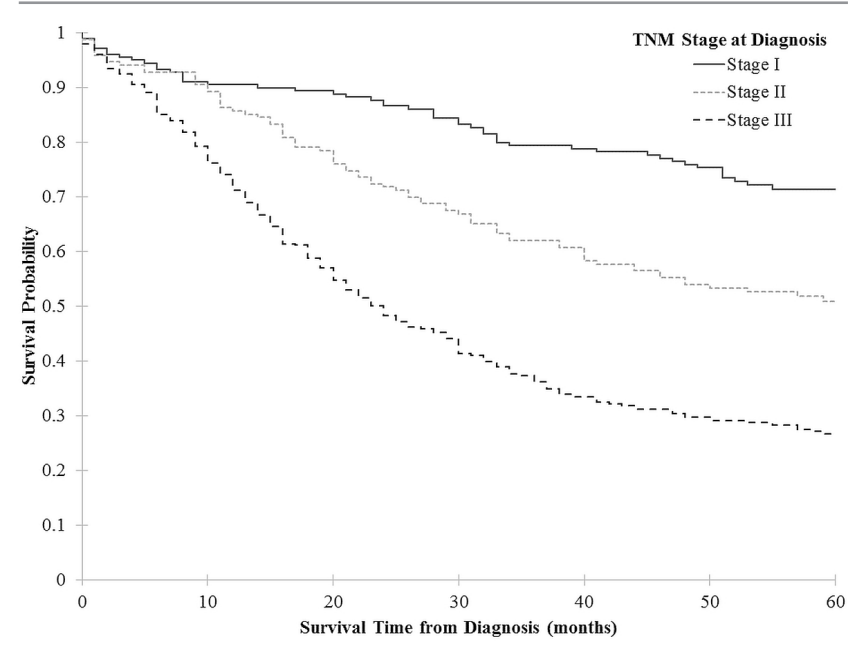

FIGURE 4 Survival by TNM stage at diagnosis (restricted to patients with stages I-III disease).

\section{DISCUSSION}

Our study describes short- and long-term perioperative outcomes for gastrectomy in the largest cohort of patients with resected stages I-III GC in Canada. The study identified significant regional variation in surgical practice patterns, including surgical approach, type of surgery, and multidisciplinary treatment with chemotherapy or radiotherapy. It also identified significant regional differences in the number of lymph nodes dissected, positive surgical margins, and operative mortality (which was alarmingly high in some areas). Geographic variation in survival was clinically meaningful; however, the differences were not statistically significant.

Intraprovincial regional variation in surgical practice patterns and outcomes for patients with stages I-III resected

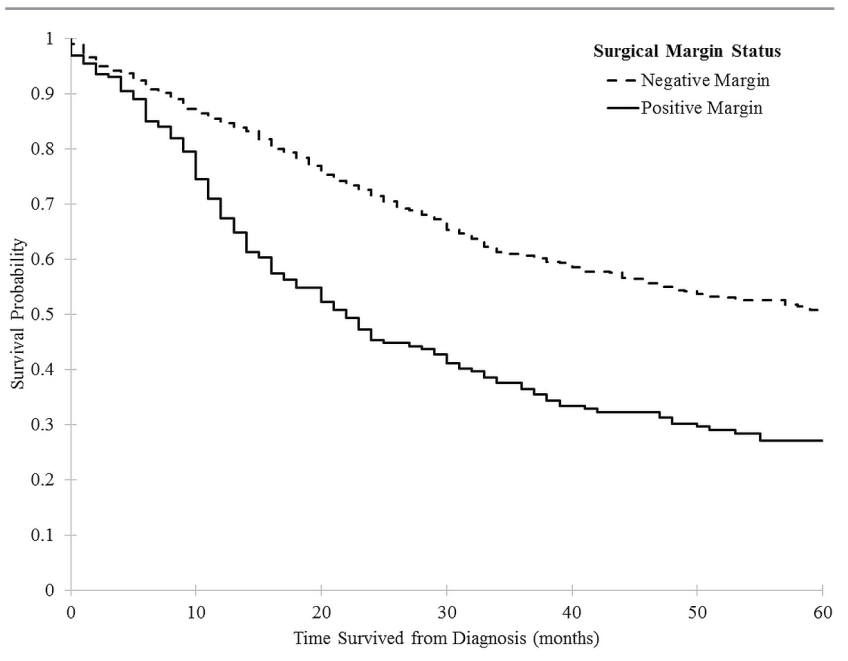

FIGURE 5 Survival by resection margin status.

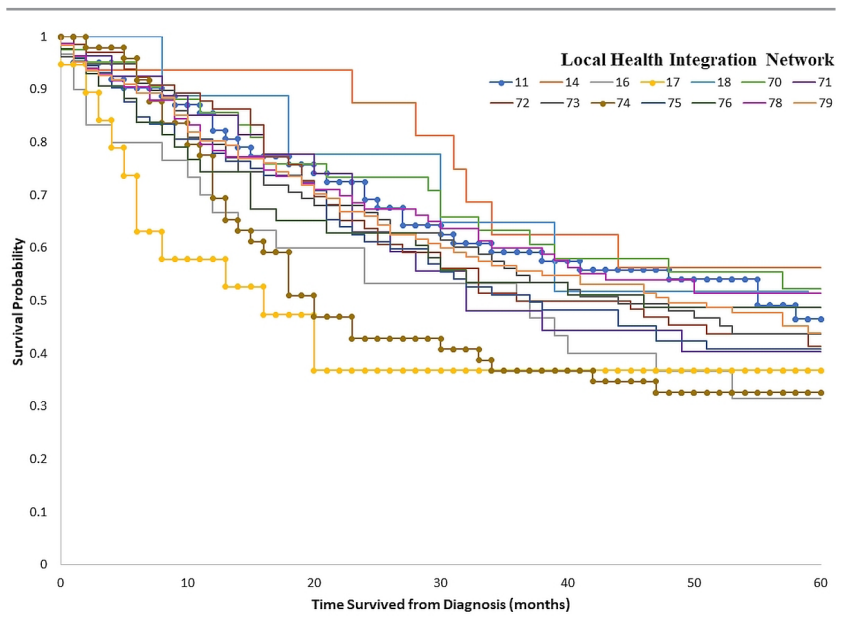

FIGURE 6 Survival by local health integration network.

GC in our study supports other research in GC care in the United States ${ }^{15,16}$, the Netherlands ${ }^{9}$, and other low-incidence countries $^{17,18}$. A comparative European study of patients with resected GC highlighted variation in operative mortality and rates of positive resection margins for England, Denmark, Sweden, and the Netherlands ${ }^{19}$. Our study found that, in some areas of Ontario, resection margins were positive in half the patients receiving a potentially curative GC resection and fewer than 16 lymph nodes were examined in almost three quarters of the patients. Positive margins and insufficient lymph node dissection are known predictors of worse outcomes for patients with GC and are contradictory to the oncologic principles of curative-intent resection. No comparative data for GC surgery are available in Canada; however, intraprovincial variation and interprovincial differences across Canada might be expected and could warrant further investigation. Understanding whether patients with positive margins or involved lymph nodes received adjuvant treatment is an important future consideration. 
The 1- and 5-year rates of os described in our study are similar to those in other studies describing worse patient outcomes in potentially curable GC in North America than in high-incidence countries such as Japan and Korea ${ }^{20-23}$. Net 5-year survival for all patients with GC is estimated to be less than $20 \%$ in Canada; however, no provincial comparator data for stage-specific outcomes are available ${ }^{24}$. Our observed median survival was similar to that reported in a cohort of patients with node-negative T1-3 disease diagnosed between 1978 and 1997 in British Columbia ${ }^{25}$. The stage-specific 5-year survival for patients with resected stages I-III GC in Ontario was slightly higher than that for a cohort of patients with surgically and non-surgically managed GC diagnosed between 2004 and 2008 in the U.S. National Cancer Database. The observed survival in our cohort was much lower than that described for a curatively resected cohort of patients in the International Gastric Cancer Association database who were diagnosed between 2000 and 2004 in Asia ${ }^{26}$. Differences in disease biology, as well as differences in surgical technique and approach, have been suggested to explain differences in prognosis between North America and Asia ${ }^{22,27,28}$. Future contemporary studies comparing interprovincial trends in os for resected GC will be necessary to understand the effect on patient outcomes of potential inequities in oncology care. Improvements in long-term outcomes over time are likely, considering possible increases in the adoption of adjuvant chemotherapy and radiotherapy.

Geographic variation might be explained by the disparate and dispersed treatment of such a rare and complex disease, paired with a lack of consensus by experts about what constituted necessary and appropriate surgical management during the era of the data being analyzed. To mitigate those issues and to improve the quality of care for patients affected by rare cancers, regional organization of care has been described in North America and Europe ${ }^{23,24}$. Regionalization or centralization of care has been shown to improve outcomes for patients with high-mortality and -morbidity diseases similar to GC, such as esophageal and pancreatic cancer ${ }^{25,29-31}$. The possible mechanisms of improvement related to regionalization are increased case volumes and thus experience for superior technical performance by surgeons and more familiarity with treatments, leading to more multidisciplinary care and better standardized processes ${ }^{25,29-31}$.

The results of the present study should be interpreted in the context of current practice, small sample sizes, and case mix. The data considered here are 10 years old and serve as an important comparator for an evaluation of current practice patterns and potential improvements in practice during the subsequent 10 years. However, aside from increased uptake of laparoscopic methods and, potentially, further uptake in adjuvant treatment and secular trends of improved surgical mortality, Gc surgical management has undergone no significant changes nationally or internationally. The data reported here serve as context for the study of future changes and for the documentation of improvements in practice following from the publication of Canadian-based guidelines ${ }^{11,32,33}$.

Our study has documented regional variation in practice patterns and outcomes. However, not all variation was statistically significant, and given limited power to detect true differences (because of the small sample size in a number of LHINs), it more likely reflects type II error. Nonetheless, Ontario has the largest number of GC cases in Canada, and the data presented include all resected cases, providing the largest cohort of resected cases in the country. Aside from increasing the number of years of data included in the study, an improvement in study power is not possible. A consideration of clinically significant differences and the effects of treating just a few patients in a particular geographic region is therefore paramount. Finally, low rates of adequate lymphadenectomy, high rates of positive margins, and possible differences in operative mortality and os must be interpreted alongside differences in case mix. Differences in tumour location, depth of tumour invasion, and stage by LHIN suggest a potential mechanism of delayed diagnosis or increased cancer aggressiveness from one LHIN to another; however, such mechanisms are unlikely to completely explain differences in outcomes. Tumour size and markers for aggressiveness were not consistently reported in the pathology and operative reports and could not be evaluated.

\section{CONCLUSIONS AND FUTURE DIRECTIONS}

Outcomes for patients with surgically resected Gc in Canada have been suboptimal. Future studies investigating temporal trends and describing contemporary practice patterns and outcomes for Canadian patients with GC are needed, especially interprovincial studies, for which no data describing or comparing outcomes are available. A better understanding of why regional variation exists will be an important first step toward improving outcomes. Within and between provinces, regional differences in disease prevention and diagnosis require intervention if outcome disparities are not entirely explained by disease biology and stage at presentation. Centralization or aggregation of research initiatives could help to reach a better understanding of equity in outcomes nationally. Quality improvement initiatives and policy-level changes to regionalize services are needed to improve patient outcomes that vary intraprovincially. Improvement in surgical management and increased uptake of adjuvant treatment could provide opportunities to optimize 5-year survival nationwide; however, reaching an understanding of why a large proportion of patients with potentially curable cancers die perioperatively is critical. Continued surveillance of the surgical indicators described in the present study could provide clinicians, patients, and policymakers with a contemporary understanding of issues in GC care quality.

\section{ACKNOWLEDGMENTS}

The research team thanks Daniela Cortinovis for her incredible work managing the provincial chart and administrative data linkage. Her perseverance and dedication were critical to the success of this project.

This research was funded by a Canadian Cancer Society grant (no. 019325). NGC has received funding (Career Scientist Award) through the Ontario Ministry of Health and Long-Term Care (монцтс) and is supported by the Hanna Family Research Chair in Surgical Oncology. This study was additionally supported by the Institute for Clinical Evaluative Sciences (ICES), which is 
funded by an annual grant from the MoHLTc. The opinions, results, and conclusions reported in this paper are those of the authors and are independent from the funding sources. No endorsement by ICES or the Ontario монцтс is intended or should be inferred. Parts of this material are based on data and information provided by Cancer Care Ontario (cCo). The opinions, results, views, and conclusions reported in this paper are those of the authors and do not necessarily reflect those of cco. No endorsement by cco is intended or should be inferred. Parts of this material are also based on data or information compiled and provided by the Canadian Institute for Health Information (сінI). However, the analyses, conclusions, opinions, and statements expressed in the material are those of the authors, and not necessarily those of cIHI.

\section{CONFLICT OF INTEREST DISCLOSURES}

We have read and understood Current Oncology's policy on disclosing conflicts of interest, and we declare that we have none.

\section{AUTHOR AFFILIATIONS}

*Department of Community Health Sciences, University of Manitoba, Winnipeg, MB; †Institute for Clinical Evaluative Sciences, ${ }^{\ddagger}$ Department of Surgery, University of Toronto, ${ }^{\circledR}$ Hospital for Sick Children, and "Institute of Health Policy, Management, and Evaluation, University of Toronto, Toronto, ON; ${ }^{\#}$ Department of Surgery, Dalhousie University, Halifax, NS; ** Odette Cancer Centre, Sunnybrook Health Sciences Centre, Toronto, ON.

\section{REFERENCES}

1. Canadian Cancer Society's Advisory Committee on Cancer Statistics. Canadian Cancer Statistics 2017. Toronto, ON: Canadian Cancer Society; 2017.

2. Mahar AL, McLeod RS, Kiss A, Paszat L, Coburn NG. A systematic review of the effect of institution and surgeon factors on surgical outcomes for gastric cancer. J Am Coll Surg 2012;214:860-8.e12.

3. Gruen RL, Pitt V, Green S, Parkhill A, Campbell D, Jolley D. The effect of provider case volume on cancer mortality: systematic review and meta-analysis. CA Cancer J Clin 2009;59:192-211.

4. Qureshi AP, Ottensmeyer CA, Mahar AL, et al. Quality indicators for gastric cancer surgery: a survey of practicing pathologists in Ontario. Ann Surg Oncol 2009;16:1883-9.

5. Helyer LK, O’Brien C, Coburn NG, Swallow CJ. Surgeons' knowledge of quality indicators for gastric cancer surgery. Gastric Cancer 2007;10:205-14.

6. Ravindran NC, Vasilevska-Ristovska J, Coburn NG, et al. Location, size, and distance: criteria for quality in esophagogastroduodenoscopy reporting for pre-operative gastric cancer evaluation. Surg Endosc 2014;28:1660-7.

7. Worhunsky DJ, Ma Y, Zak Y, et al. Compliance with gastric cancer guidelines is associated with improved outcomes. $J$ Natl Compr Canc Netw 2015;13:319-25.

8. Coburn NG, Swallow CJ, Kiss A, Law C. Significant regional variation in adequacy of lymph node assessment and survival in gastric cancer. Cancer 2006;107:2143-51.

9. Ho VK, Damhuis RA, Hartgrink HH. Adherence to national guidelines for gastric cancer in the Netherlands: a retrospective population-based audit. Int J Cancer 2013;132:1156-61.

10. Coburn NG, Lourenco LG, Rossi SE, et al. Management of gastric cancer in Ontario. J Surg Oncol 2010;102:54-63.

11. Coburn N, Cosby R, Klein L, et al. on behalf of the Surgical Management of Gastric Cancer Guideline Development Group. Staging and Surgical Approaches in Gastric Cancer. Guideline 2-19. Toronto, ON: Cancer Care Ontario; 2017.

12. Waddell T, Verheij M, Allum W, Cunningham D, Cervantes A, Arnold D. Gastric cancer: ESMO-ESSO-ESTRO clinical practice guidelines for diagnosis, treatment and follow-up. Eur J Surg Oncol 2014;40:584-91.
13. NationalComprehensiveCancerNetwork (NCCN).NCCNClinical Practice Guidelines in Oncology: Gastric Cancer. Ver. 2.2018. Fort Washington, PA: NCCN; 2018. [Current version available online at: https://www.nccn.org/professionals/physician_gls/pdf/ gastric.pdf (free registration required); cited 24 July 2018]

14. Mahar AL, Coburn NG, Kagedan DJ, Viola R, Johnson AP. Regional variation in the management of metastatic gastric cancer in Ontario. Curr Oncol 2016;23:250-7.

15. Snyder RA, Penson DF, Ni S, Koyama T, Merchant NB. Trends in the use of evidence-based therapy for resectable gastric cancer: trends in gastric cancer treatment.JSurgOncol 2014;110:285-90.

16. Al-Refaie WB, Gay G, Virnig BA, et al. Variations in gastric cancer care: a trend beyond racial disparities. Cancer 2010;116:465-75.

17. Jaworski R, Bollschweiler E, Holscher AH, et al. Prognostic relevance of demographics and surgical practice for patients with gastric cancer in two centers: in Poland versus Germany. Gastric Cancer 2011;14:234-41.

18. Herbreteau E, Jooste V, Hamza S, Lepage C, Faivre J, Bouvier AM. Trends in themanagement of gastric cancer over a 32-year period: a French population-based study. Gastric Cancer 2015;18:129-37.

19. Dikken JL, van Sandick JW, Allum WH, et al. Differences in outcomes of oesophageal and gastric cancer surgery across Europe. Br J Surg 2013;100:83-94.

20. Dicken BJ, Bigam DL, Cass C, Mackey JR, Joy AA, Hamilton SM. Gastric adenocarcinoma: review and considerations for future directions. Ann Surg 2005;241:27-39.

21. Izuishi $\mathrm{K}, \mathrm{Mori} \mathrm{H}$. Recent strategies for treating stage Iv gastric cancer: roles of palliative gastrectomy, chemotherapy, and radiotherapy. J Gastrointestin Liver Dis 2016;25:87-94.

22. Strong VE, Song KY, Park CH, et al. Comparison of diseasespecific survival in the United States and Korea after resection for early-stage node-negative gastric carcinoma.JSurg Oncol 2013;107:634-40.

23. Hundahl SA, Phillips JL, Menck HR. The National Cancer Data Base report on poor survival of US gastric carcinoma patients treated with gastrectomy. Cancer 2000;88:921-32.

24. American Joint Committee on Cancer. AJCC Cancer Staging Manual. 8th ed. Cham, Switzerland: Springer International Publishing; 2017.

25. Shim JH, Song KY, Jeon HM, et al. Is gastric cancer different in Korea and the United States? Impact of tumor location on prognosis. Ann Surg Oncol 2014;21:2332-9.

26. Strong VE, Wu AW, Selby LV, et al. Differences in gastric cancer survival between the U.S. and China. JSurg Oncol2015;112:31-7.

27. Ray-Coquard I, Lauraine EP, Le Cesne A, et al. Improving treatment results with reference centres for rare cancers: where do we stand? Eur J Cancer 2017;77:90-8.

28. Wouters M, Karim-Kos H, le Cessie S, et al. Centralization of esophageal cancer surgery: does it improve clinical outcome? Ann Surg Oncol 2009;16:1789-98.

29. Finley CJ, Jacks L, Keshavjee S, Darling G. The effect of regionalization on outcome in esophagectomy: a Canadian national study. Ann Thorac Surg 2011;92:485-90.

30. Anaya DA, Malafa M. Outcome disparities in pancreatic cancer: need for improved regionalization of care. JAMA Surg 2016;151:345-6.

31. Lemmens V, Bosscha K, van der Schelling G, Brenninkmeijer S, Coebergh J, de Hingh I. Improving outcome for patients with pancreatic cancer through centralization. Br J Surg 2011;98:1455-62.

32. Brar S, Law C, McLeod R, et al. on behalf of the International multidisciplinary expert panel. Defining surgical quality in gastric cancer: a RAND/UCLA appropriateness study. J Am Coll Surg 2013;217:347-57.e1.

33. Coburn N, Seevaratnam R, Paszat L, etal. Optimal management of gastric cancer: results from an international RAND/UCLA expert panel. Ann Surg 2014;259:102-8. 